\title{
Anatomic Study of Pterygomaxillary Junctions in Koreans
}

\author{
Dong-Yul Kim, Yeong-Cheol Cho, Iel-Yong Sung, Dae-Kawn Yun, Min-Uk Kim, \\ Ji-Uk Kim, Hyung-Suck Son, Jang-Ho Son
}

Department of Oral and Maxillofacial Surgery, Ulsan University Hospital, University of Ulsan College of Medicine

\section{Abstract}

Purpose: This study is to evaluate the location of descending palatine artery, the anatomy of pterygomaxillary junction, and the association between the obtained anatomic values and several variables.

Methods: We studied 40 patients who were treated for dentofacial deformites from January 2010 to December 2012 in Ulsan University Hospital, Ulsan, Korea. Cone beam computed tomogram (CBCT) was done for all patients. The reference point was approximately 5 to $7 \mathrm{~mm}$ above anterior nasal spine on axial image. We evaluated the location of the greater palatine canal (line a: on the coronal view, the shortest line between the center of greater palatine canal and pterygoid fossa; distance a: the distance of line a). We also measured the thickness (line b: on the coronal view, the shortest line between maxillary posterior sinus wall and pterygoid fossa; distance b: distance of line b), width (line c: on the coronal view, the line perpendicular to the line $\mathrm{b}$ and the nearest line from the most concave point of lateral pterygoid plate to the medial pterygoid plate; distance c: distance of line c) and height (line d: on sagittal view, the vertically longest line of pterygoid junction; distance $\mathrm{d}$ : the distance of line d) in pterygomaxillary junctions. We evaluated the association between the obtained anatomic values and several variables (sex, age, height and weight).

Results: The mean distance a was $4.78 \mathrm{~mm}$, mean distance b was $5.53 \mathrm{~mm}$, mean distance c was $8.01 \mathrm{~mm}$ and mean distance $\mathrm{d}$ was $13.22 \mathrm{~mm}$. The differences between age and mean distance $\mathrm{c}$ and weight and mean distance $\mathrm{d}$ in pterygomaxillary junctions are statistically significant.

Conclusion: There apparently is anatomic variation of pterygomaxillary junctions by various values, particularly weight and age in a Korean clinical population.

Key words: Anatomy, Osteotomy, Le Fort, Maxilla, Sphenoid bone

\section{Introduction}

Von Langenbach first suggested the Le Fort I osteotomy in 1859 for treatment of nasopharyngeal polyp. After Le Fort announced the laboratory work on the patterns of facial fractures in 1901, Wassmund began to use the Le
Fort I osteotomy for the correction of midfacial deformities in $1927[1,2]$. However he did not separate the pterygomaxillary junction. Instead, he selected postoperative elastic traction to reposition the maxilla to the desired position. In 1934, Axhausen suggested total mobilization of the maxilla, and Schuchardt first performed surgical separation of

RECEIVED October 24, 2013, REVISED November 10, 2013, ACCEPTED November 26, 2013

Correspondence to Jang-Ho Son

Department of Oral and Maxillofacial Surgery, Ulsan University Hospital, University of Ulsan College of Medicine

877 Bangeojinsunhwan-doro, Dong-gu, Ulsan 682-714, Korea

Tel: 82-52-250-8823, Fax: 82-52-250-7236, E-mail: glycerol@naver.com

(C) This is an open access article distributed under the terms of the Creative Commons Attribution Non-Commercial License (http://creativecommons. org/licenses/ by-nc/3.0) which permits unrestricted non-commercial use, distribution, and reproduction in any medium, provided the original work is properly cited. 
pterygomaxillary junction. Since then, Le Fort I osteotomy has become the standard procedure to manage various dentofacial deformities. Although the decision for the surgical separation of the pterygomaxillary junction during Le Fort I osteotomy is still controversial, it seems to be important to separate the pterygoid plate of sphenoid bone from maxilla precisely[3]. Even though Le Fort I osteotomy is the most popular method, there can be complications. Besides frequently occurring complications such as intraoperative and postoperative hemorrhage, infection, nerve injury, oronasal fistula formation, relapse, dental injury, there may be uncommon complications such as visual function, respiratory function, and unusual vascular injury[1]. Apart from hemorrhage from sphenopalatine artery, descending palatine artery and maxillary artery, unwanted complication like stroke, arteriovenous fistula and ophthalmic damage may be associated with the unwanted pterygomaxillary separation or maxillary downfracture[4].

There are various methods and instruments to separate pterygoid plates from maxilla although there is controversy regarding the surgical separation of the pterygomaxillary junction. Usually technique is selected based on the operating surgeon's preference. Anatomic variation such as bony defect or incomplete ossification at the skull base, thickness variation of the posterior wall of the maxilla or pterygoid plate might be reasons for complications during separation of pterygomaxillary junction. Especially in patients with dentofacial deformities, trauma, or a history of orthognathic surgery, who have more anatomic variation, the risk of complications is much higher[5].
As we have reviewed so far, there are many complications associated with separation of pterygomaxillary junction or downfracture of maxilla. Therefore, we have to understand the anatomy of pterygomaxillary junction to minimize the complications relevant to Le Fort I osteotomy[6].

This study evaluated the location of descending palatine artery, the anatomy of pterygomaxillary junction, and the association between the obtained anatomic values and several variables (sex, age, height and weight).

\section{Materials and Methods}

\section{Patients}

Forty patient (20 men and 20 women) treated for maxillofacial deformities from January 2010 to December 2012 in Ulsan University Hospital (Ulsan, Korea) were included in this study. They averaged 25.5 years old, $167.97 \mathrm{~cm}$ tall, and $63.69 \mathrm{~kg}$ in weight. We investigated the location of descending palatine artery and anatomy of pterygomaxillary junction on both right and left aspect of 40 patients.

This retrospective study was conducted by reviewing chart and radiographic dates and exempted from approval of institutional review board of the institute.

\section{Methods}

All patient underwent cone beam computed tomogram (CBCT). We took the CBCT at $120 \mathrm{kV}, 10 \mathrm{~mA}$, field-of-view $240 \times 190$, Voxel size $0.2 \mathrm{~mm}$. The reference point was
A

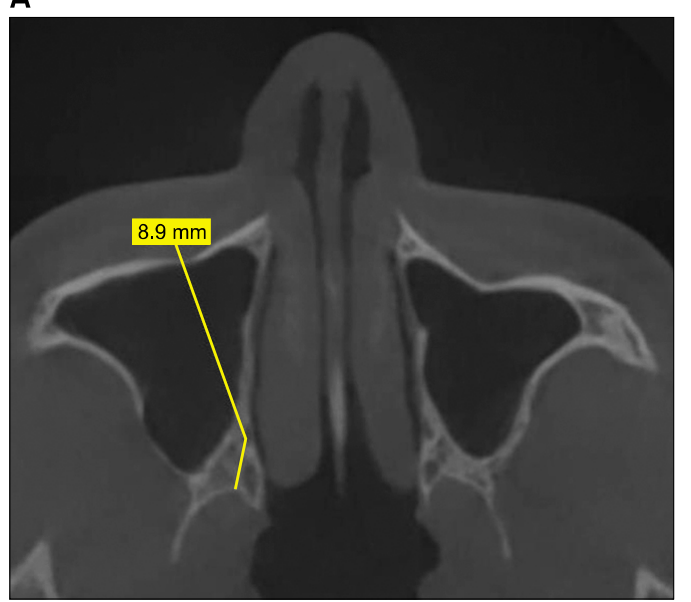

B

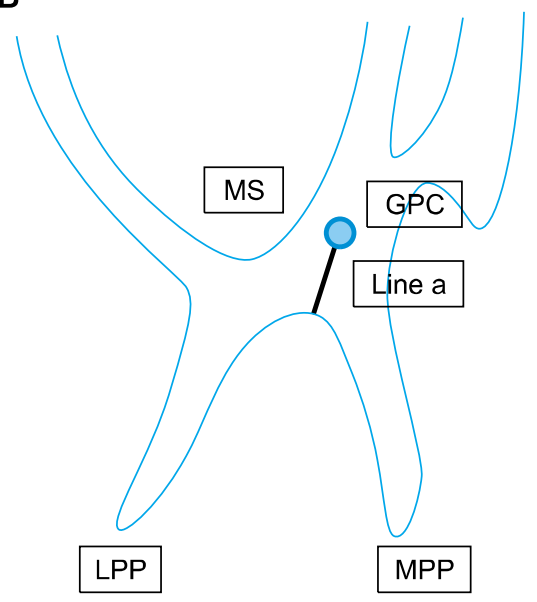

Fig. 1. (A) Line $a$ is the shortest line between the center of greater palatine canal and pterygoid fossa on the coronal view, distance $a$ is the distance of line a. (B) Diagram of $A$. MS, maxillary sinus; GPC, greater palatine canal; MPP, medial pterygoid plate; LPP, lateral pterygoid plate. 
approximately 5 to $7 \mathrm{~mm}$ above anterior nasal spine on axial image. We measured the location of the descending palatine artery (line a). Line a is the shortest line between the center of greater palatine canal and pterygoid fossa and the distance $\mathrm{a}$ is the length of line a on the coronal view (Fig. 1). We calculated the thickness of pterygomaxillary junction (line b). Line b is the shortest line between maxillary posterior sinus wall and pterygoid fossa and distance $\mathrm{b}$ is the length of line $\mathrm{b}$ on the coronal view. We also measured the width of pterygomaxillary junction (line c). Line $\mathrm{c}$ is the line perpendicular to the line $\mathrm{b}$ and the nearest line from the most concave point of lateral pterygoid plate to the medial pterygoid plate and distance $c$ is the length of line $\mathrm{c}$ on the coronal view (Fig. 2). On the sagittal plane, we measured the height of pterygomaxillary junction (line $\mathrm{d}$ ). Line $\mathrm{d}$ is the vertically longest line of pterygoid junction and distance $d$ is the length of line d (Fig. 3). We estimated the association between the anatomic values and several variables (sex, age, height and weight).

We used SPSS Statistics for Windows ver. 21 (IBM Co., Armonk, NY, USA) to do the Kruskal-Wallis test and Student's t-test. We rejected null hypotheses of no difference if $P$-values were less than 0.05 .

\section{Results}

\section{Mean distance $(\mathrm{mm})$ of pterygomaxillary junctions}

The mean distance between the center of greater palatine canal (mean a) was $4.78 \mathrm{~mm}$. The mean thickness (mean b) was $5.53 \mathrm{~mm}$, mean width (mean c) was $8.01 \mathrm{~mm}$ and mean height (mean d) was $13.22 \mathrm{~mm}$ in pterygomaxillary junctions (Table 1).
A

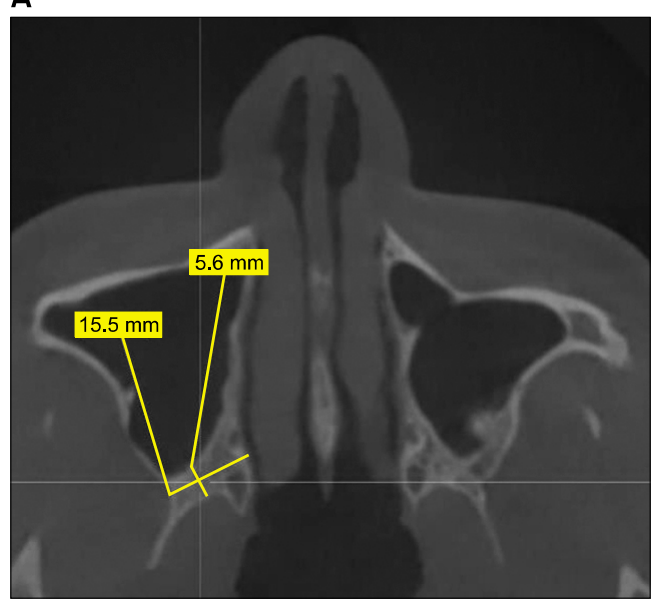

A

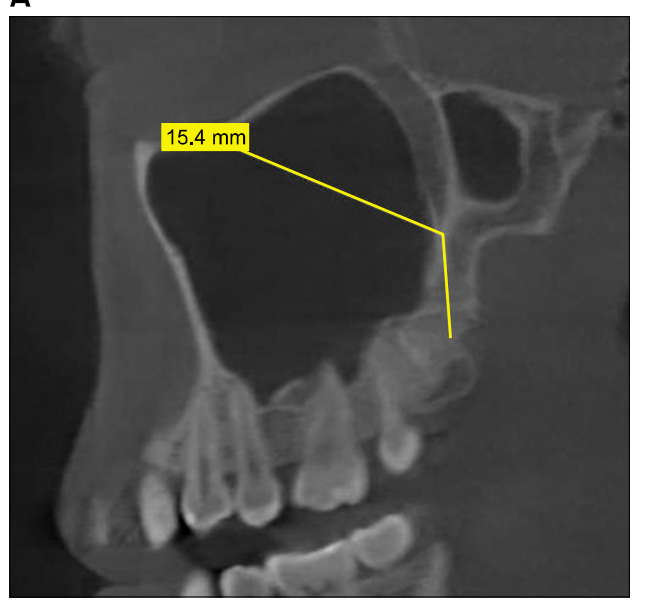

B

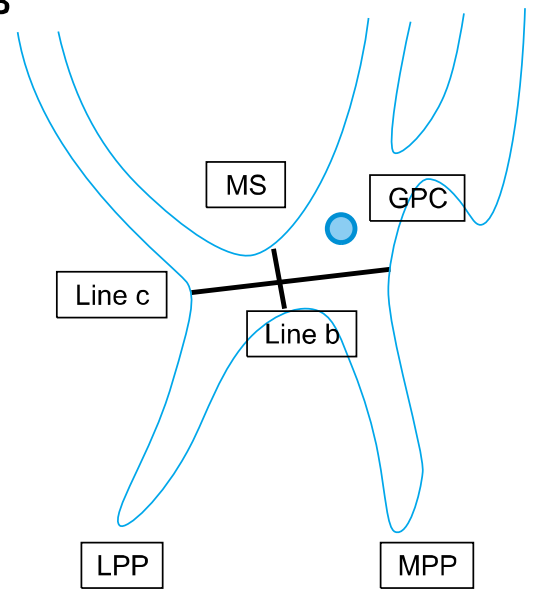

Fig. 2. (A) Line $b$ is the shortest line between maxillary posterior sinus wall and pterygoid fossa on the coronal view, distance $b$ is the distance of line $b$; line $c$ is perpendicular to the line $b$ and the nearest line from the most concave point of lateral pterygoid plate to the medial pterygoid plate on the coronal view, distance $c$ is the distance of line $c$. (B) Diagram of A. MS, maxillary sinus; GPC, greater palatine canal; MPP, medial pterygoid plate; LPP, lateral pterygoid plate.

B

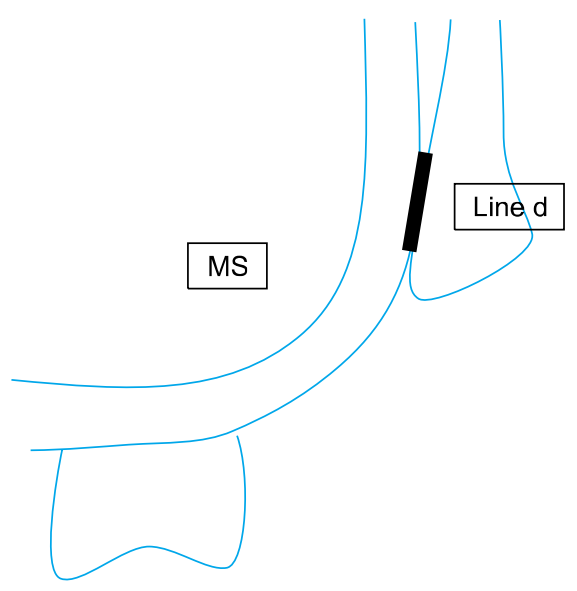

Fig. 3. (A) Line $d$ is the vertically longest line of pterygoid junction on the sagittal view, distance $d$ is the distance of line d. (B) Diagram of $A$. MS, maxillary sinus. 
Table 1. Mean distance of pterygomaxillary junctions and statistical significance by sex, weight, age and height

\begin{tabular}{|c|c|c|c|c|}
\hline Variable & Mean a $(\mathrm{mm})$ & Mean b (mm) & Mean c $(\mathrm{mm})$ & Mean $\mathrm{d}(\mathrm{mm})$ \\
\hline All subject $(n=80)$, right and left & 4.78 & 5.53 & 8.01 & 13.22 \\
\hline \multicolumn{5}{|l|}{ Sex } \\
\hline Male $(n=40)$ & 5.09 & 5.81 & 7.39 & 12.98 \\
\hline Female $(n=40)$ & 4.47 & 5.24 & 8.62 & 13.46 \\
\hline Significance probability & 0.236 & 0.136 & 0.356 & 0.478 \\
\hline \multicolumn{5}{|l|}{ Weight $(\mathrm{kg})$} \\
\hline $40 \sim 50 \quad(n=6)$ & 4.28 & 5.01 & 9.21 & 10.23 \\
\hline $50 \sim 60(n=32)$ & 4.97 & 5.57 & 7.67 & 12.51 \\
\hline $60 \sim 70 \quad(n=24)$ & 4.75 & 5.40 & 8.28 & 14.20 \\
\hline $70 \sim 80(n=12)$ & 5.23 & 6.51 & 7.62 & 13.85 \\
\hline$>80 \quad(n=6)$ & 3.45 & 4.31 & 8.21 & 14.78 \\
\hline Significance probability & 0.460 & 0.495 & 0.736 & 0.023 \\
\hline \multicolumn{5}{|l|}{ Age $(y r)$} \\
\hline $10 \sim 19(n=12)$ & 4.56 & 5.96 & 6.95 & 10.80 \\
\hline $20 \sim 29(n=48)$ & 5.10 & 5.30 & 8.65 & 13.43 \\
\hline $30 \sim 39(n=20)$ & 3.89 & 5.49 & 8.04 & 13.60 \\
\hline Significance probability & 0.066 & 0.451 & 0.002 & 0.207 \\
\hline \multicolumn{5}{|l|}{ Height $(\mathrm{cm})$} \\
\hline $150 \sim 159(\mathrm{n}=24)$ & 4.54 & 5.13 & 8.54 & 12.31 \\
\hline $160 \sim 169(n=18)$ & 4.71 & 6.02 & 7.85 & 13.86 \\
\hline $170 \sim 179(n=26)$ & 4.98 & 5.43 & 7.72 & 12.78 \\
\hline $180 \sim 189(n=12)$ & 4.95 & 5.76 & 7.76 & 14.98 \\
\hline Significance probability & 0.645 & 0.614 & 0.736 & 0.082 \\
\hline
\end{tabular}

Mean a: average of distance a; mean distance between the center of greater palatine canal and pterygoid fossa and it means the location of descending palatine canal, Mean b: average of distance b; the mean thickness of pterygomaxillary junctions, Mean c: average of distance c; the mean width of pterygomaxillary junctions, Mean d: average of distance $\mathrm{d}$; the mean height of pterygomaxillary junctions.

\section{Statistical significance}

None of the measured anatomic values were associated with sex or height. However, mean $\mathrm{d}$ and weight were significantly associated $(P<0.005)$, as were mean $c$ and age $(P<0.02)$ (Table 1$)$.

\section{Discussion}

Complications often arise during separation of pterygomaxillary junctions and downfracture of maxilla. Bendor-Samuel et al.[1] reported three rare complications associated with Le Fort I osteotomy. In the first case, unilateral third nerve palsy occurred from iatrogenic carotid cavernous fistula and false aneurysm of the internal carotid artery after treating maxillary hypoplasia secondary to a bilateral complete cleft of the primary and secondary palate. In the second case, there was total unilateral blindness not related with an orbital apex syndrome after midface hypoplasia surgery secondary to a complete cleft of the primary and secondary palate. The third case was unilateral total avulsion of a lateral segment of the palate after managing a complete bilateral cleft of the primary and secondary palate. He reported that complications asso- ciated with Le Fort I osteotomy arise at a rate of about $5 \%$ to $6 \%$. However, sometimes uncommon complications occur that can be devastating. For reducing severe rare consequences, greater caution is needed when separating the pterygomaxillary junction[1].

Cheng et al.[2] reported that the visual loss was a rare complication but might occur after Le Fort I osteotomy. Such an outcome results from ischemia, an infarction of the ophthalmic artery caused by unpredictable fracture, rupture of an ophthalmic aneurysm, massive hemorrhage from the descending palatine artery or sphenopalatine artery, hypotensive anesthesia (which may be embolism of the vessel, decreasing the blood supply to the retina and choroid), inappropriate pressure on the eyeball, or abnormality of the internal carotid artery. When unwanted fracture of pterygomaxillary junction occurs, it can extend to pterygoid plate, sphenoid bone, orbital floor, optic canal or skull base. This extension may have an effect on the optic nerve or its vascular supply. In addition, a hemorrhage from palatine fossa may flow into the orbital cavity through the inferior orbital fissure and compress the globe inappropriately[2].

Cruz and dos Santos[7] also reported a case of blindness after Le Fort I osteotomy. Possibly the force while separat- 
ing the pterygomaxillary junction can spread to the sphenoid bone situated at the intra- and extracranial portion of the skull base. This may damage the optic, cranial nerve and branches of the carotid artery. He classified the complication associated with the skull base into four categories (functional loss of the lacrimal gland, cranial nerve palsies, damage to the internal carotid artery and loss of vision) and suggested complete separation between maxilla and pterygoid plate prior to mobilization of the maxilla to minimize these complications.

Kim et al.[8] reported a 19-year-old man suffered various cranial nerve injuries after Le Fort I osteotomy. The complications were impairment of outward movement of the eye, decrease of vision and paresthesia of the frontal and upper cheek area, all associated with damage of abducent, optic, opthalmic and maxillary nerve. He commented that these complications might occur due to unwanted fracture of sphenoid bone while separating the pterygomaxillary junction, resulting in damage to the cavernous sinus.

Bhaskaran et al.[9] reported a 19-year-old female with cerebrospinal fluid leakage after Le Fort I osteotomy that may have resulted from an unintended fracture of pterygoid plate near the skull base.

Intraoperative and postoperative hemorrhage may result from venous and arterial injuries. The most frequent cause of venous hemorrhage develops from the pterygoid plexus, following damage to the pterygoid muscle. The maxillary artery and its branches are most likely to be injured through the pterygopalatine fossa during separation of maxillary tuberosity and pterygoid plate by osteotome or downfracture of maxilla. The posterior superior alveolar artery is located in the posterolateral wall of the maxilla and the descending palatine artery is in perpendicular plate of palatine bone and passes into the greater palatine canal. Both arteries can be damaged from Le Fort I osteotomy. Injury to the posterior alveolar artery does not result in major hemorrhage. However, the descending palatine artery situated at the posteromedial wall of maxillary sinus can be a source of massive hemorrhage if damaged[10].

O'Regan and Bharadwaj[11] reported eleven (18\%) of the surgeons among the 205 oral and maxillofacial surgeons experienced a serious vascular complication in the United Kingdom in 2004 through the questionnaire. These severe complications were associated with injury of the maxillary artery.

Newhouse et al.[12] published a case of life-threatening intraoperative hemorrhage from pterygoid plate separation. After surgery the patient had a traumatic arteriovenous fistula between the right internal carotid artery and the internal jugular vein at the skull base. There is no intracranial flow from the right internal carotid artery. Despite the patient's stable condition, he had vagus and hypoglossal nerve damage and left hemiparesis.

Albernaz and Tomsick[13] reported two cases of arteriovenous fistula associated with maxillary artery after Le Fort I osteotomy. In both cases the fistula were successfully embolized, leading to complete recovery from symptoms. The problem may have been the result of an extension of an unwanted fracture on the pterygomaxillary junction into the pterygomandibular fossa.

Habal[14] documented a 28-year-old Caucasian woman who had a carotid cavenous fistula after midface advancement for an open bite and maxillary retrusion using Le Fort I osteotomy.

If surgeons understand the anatomic location of the relevant arteries, they can reduce bleeding complications from arterial damage. Furthermore they can maintain sufficient blood supply to the osteotomized maxilla[15].

Anatomic variations of the descending palatine arteries can occur. Li et al.[16] studied the anatomy associated with descending palatine artery in 30 human dry skulls. They found that the mean length was $10 \mathrm{~mm}$ (range, 6 to 15 $\mathrm{mm}$ ) between the greater palatine canal and nasal floor, $38.4 \mathrm{~mm}$ (male; range, 34 to $42 \mathrm{~mm}$ ) and $34.6 \mathrm{~mm}$ (female; range, 28 to $43 \mathrm{~mm}$ ) between the piriform rim to the descending palatine artery. They noted that the greater palatine canal was placed between first and third molar. They suggested that osteotomy should be conducted inside above ranges to avoid damage to the descending palatine artery and recommended that excessive angulation of the plane of disjunction be abandoned. The mean length from internal greater palatine canal to pterygomaxillary fissure was $6.6 \mathrm{~mm}$ (range, 2 to $10 \mathrm{~mm}$ ). Because in our study the average distance between pterygomaxillary junction and greater palatine canal was about $4.78 \mathrm{~mm}$, we confirmed the anatomic variation associated with location of descending palatine arteries by race. These variations by race were also reported by Lee et al.[17] They documented 
a mean length of $30 \mathrm{~mm}$ (male: $27 \mathrm{~mm}$, female: $10 \mathrm{~mm}$ ) from the piriform rim to the descending palatine artery.

There have been many studies of the association between anatomic variations and fracture of the pterygoid plate. Kanazawa et al.[18] documented the pattern of dysjunction after Le Fort I osteotomy for 50 patients diagnosed with mandibular prognathism. Le Fort I osteotomy without the use of an osteotome during pterygomaxillary separation was performed for all patients. Most of the disjunction occurred on the maxillary tuberosity (48.0\%). Twenty-eight pterygoid plates were fractured. Male gender, increased age, thickness of pterygomaxillary junction and length of the maxillary tuberosity were significant risk factors for the fracture. When the thickness of the pterygomaxillary junction was less than $2.6 \mathrm{~mm}$ and length of maxillary tuberosity more than $11.5 \mathrm{~mm}$, the pterygoid plate was easily fractured.

Hwang et al.[19] reported mean thickness, width and concavity of pterygomaxillary junction in 30 Korean dry skulls. The pterygomaxillary junctions were separated with a curved osteotome. Disjunction and fracture groups were classified according to separation of maxillary tuberosity from medial and lateral pterygoid plates. They concluded that the thin pterygomaxillary junction or deeply concave pterygomaxillary fissure is more vulnerable to fracture. The mean width $(7.21 \pm 2.35 \mathrm{~mm})$, thickness $(4.70 \pm 2.60 \mathrm{~mm})$ and concavity $(1.09 \pm 0.53 \mathrm{~mm})$ of pterygomaxillary junctions in the fractured group were measured.

Lee et al.[20] evaluated the anatomy of the pterygomaxillary junction of 20 patients with cleft lip and palate (CLP). They concluded that patients with CLP had larger and thicker pterygomaxillary structure and might be more resistant to pterygomaxillary disjunction.

We measured the location of descending palatine artery (mean a), $4.78 \mathrm{~mm}$ and evaluated the thickness (mean b), $5.53 \mathrm{~mm}$, the width (mean c), $8.01 \mathrm{~mm}$ and the height (mean d), $13.22 \mathrm{~mm}$ in pterygomaxillary junctions. The osteotomy may need to extend $8 \mathrm{~mm}$ in horizontal plane and $13 \mathrm{~mm}$ in the vertical plane. We also assessed the association between the obtained anatomic values and several variables (sex, age, weight and height). None of the measured anatomic values were associated with sex or height. However, mean $\mathrm{d}$ and weight were significantly associated $(P<0.005)$, as were mean $c$ and age $(P<0.02)$.
Older people have a wider pterygomaxillary junction in the horizontal plane and the heavier people have longer pterygomaxillary junctions in the vertical plane. Moreover, the width of pterygomaxillary junction (mean c) was 6.95 $\mathrm{mm}$ in the patients who were younger than 19 years old. We found no significant association between the thickness of the pterygomaxillary junction and weight. However, the mean b was $4.31 \mathrm{~mm}$ in patients who weighed over 80 kg. More attention about unwanted fracture of pterygomaxillary junctions may be needed during the procedure in these patients.

Robinson and Hendy[21] reported fractures of the pterygoid plates and subsequent disruption of the pterygopalatine fossa during separation of the pterygomaxillary junction by curved Obwegeser chisel. That event caused the damage of pterygopalatine fossa, resulting in injuries to the maxillary artery and its branches.

Various techniques have been developed to prevent risks. Lanigan and Guest[4] studied five alternative approaches to the pterygomaxillary separation in 50 fresh cadavers. In their study high-level pterygoid plate fractures were rebased as those that occurred at or near the base of the skull, low level fractures were at the level of osteotomy cut and intermediate level fractures were slightly above the level of the osteotomy cut. Ideal or near ideal separation was defined as complete separation between the maxillary tuberosity, pyramidal process of the palatine bone and the pterygoid plate, or separation such that the tiny segment of the plates attached inferiorly are left, but the remnant of the pterygoid plates are intact and maintained to the base of the skull superiorly. When using a curved osteotome, ideal separation of pterygoid plate occurred in 3/20 (15\%) sides and high-level separation of near the skull base occurred in 5/20 sides (25\%). Otherwise, when using a micro-oscillating saw, ideal separation was $14 / 20 \%$ (70\%) sides with no high level separation. In the latter no vascular injury was reported. They suggested that use of a large, heavy osteotome between the maxillary tuberosity and pterygoid plate produced dull, extensive damage. Conclusively they recommended micro-oscillating saw instead of curved Obwegeser osteotome for separation of pterygomaxillary junction. They published a number of anatomic variations from 50 fresh cadavers. 
Lanigan and Loewy[5] evaluated the type of pterygomaxillary separation through the postoperative computed tomography scan after Le Fort I osteotomy by micro-oscillating saw in 16 patients. Idea and near ideal separation occurred in 26/32 sides (81\%) and low-level separation reported in 6 sides (19\%). They suggested that separation between the maxillary tuberosity and pterygoid plates by micro-oscillating saw would minimize the potential strain during the maxillary downfracture and decrease the possibility of extension of unwanted fracture to the base of the skull. They commented that a thick, heavy pterygomaxillary junction and thin skull base would be vulnerable to fracture during the maxillary downfracture.

Trimble et al.[22] suggested a modification in low-level maxillary osteotomy. The cut was made through the tuberosity, ending at the posterior aspect of the hard palate and medial, anterior to the pterygomaxillary junction. They insisted that the advantage of the method was that the risk of vascular damage was decreased, the mobility of posterior segments was increased, and abundant blood supply such as maxillary artery and its branches were maintained.

Cheng and Robinson[23] performed pterygomaxillary separation after Le Fort I osteotomy using swan's neck osteotomy in 12 cadavers with patients. The pterygoid plate were fractured in 9/24 pterygomaxillary junction. Multiple fracture occurred among these fractured separations. All fracture levels were at the level of the osteotomy cut and no high level fracture occurred. They suggested that use of swan's neck osteotomy could reduce unwanted fractures compared to the traditional method. There was no association between the pattern of fracture and sex, age, or dental state.

Precious et al.[24] separated pteygomaxillary junction by Tessier spreading forceps without osteotomy in 500 cases. They defined type 1 as complete separation of the maxilla from the pterygoid process. Type 1 separation occurred in $83 \%$ of cases. Based on this, they insisted that separation without the use of an osteotome prevents fracture of medial pterygoid plate and injury of the adjacent vascular structure.

Stajcić[25] reported that the method with increased angulation $\left(80^{\circ}\right)$ of the curved osteotome to the sagittal plane reduces the possibility of pterygoid plate fracture compared to the most popular method with angulation (approximately $50^{\circ}$ ). However the technique was not recommended due to causing unwanted fracture of palatine bone and mobility of fractured pterygoid segment posteriorly. They classified 20 dry human skulls into two types: a fissure and synostosis according to the variation in the shape and thickness of the pterygoid plates. Synostosis is associated with greater risk of unwanted fracture.

Laster et al.[6] reported a variety of complications associated with pterygomaxillary disjunction and emphasized a thorough understanding of the anatomy in the pterygomaxillary junction to reduce these complications. They also published separation of pterygomaxillary junction with shark fin osteotome in 10 adult patients. Obwegeser osteotomy was used for pterygomaxillary disjunction on one side of pterygomaxillary, and shark fin osteotome on the opposite side. Complete or near complete separation occurred with shark fin osteotome, otherwise high level separation was shown in $5 / 10(50 \%)$. The reason was that due to the Laster 'shark fin' osteotome with a double perpendicular blade, so the line of osteotome in the horizontal plane met the vertical plane of the pterygomaxillary fissure. They suggested that direct force was applied on the junction and the risk of pterygoid plate fracture or skull base fracture was diminished.

Besides these methods, Landes et al.[26] introduced the osteotomy of pterygomaxillary junction with piezoelectricity and Ueki et al.[27] advocated the method with ultrasonic bone curette for pterygomaxillary disjunction.

\section{Conclusion}

Complications of orthognathic surgery may occur from separation of pterygomaxillary junctions and downfracture of maxilla. Although there has been some controversy, many appliances and methods have been developed to minimize the complications. Understanding the anatomic variation of the pterygomaxillary junctions may be the most important factor when applying them safely.

We studied the location of descending palatine artery, the anatomy of pterygomaxillary junction, and the association between the obtained anatomic values and several variables (sex, age, weight and eight).

Our conclusions are as below. 
1. Statistical significance was observed when it comes to the weight and mean $\mathrm{d}$ (the height) $(P<0.005)$ and the age and mean $c$ (the width) $(P<0.02)$. Thus, older people have a wider pterygomaxillary junction in the horizontal plane and heavier people (over $80 \mathrm{~kg}$ ) have longer pterygomaxillary junction in the vertical plane.

2 . We measured the location of descending palatine artery (mean a), $4.78 \mathrm{~mm}$ and also evaluated the thickness (mean b), $5.53 \mathrm{~mm}$, the width (mean c), $8.01 \mathrm{~mm}$ and the height (mean d), $13.22 \mathrm{~mm}$ in pterygomaxillary junctions. As a result, the osteotomy may be needed to extend $8 \mathrm{~mm}$ in horizontal plane and $13 \mathrm{~mm}$ in the vertical plane.

3. More attention about unwanted fracture of pterygomaxillary junctions may be needed during the osteotomy in the patients who are younger than 19 years old and who weigh over $80 \mathrm{~kg}$.

From this useful information, we may minimize the various errors that can occur during surgery.

\section{References}

1. Bendor-Samuel R, Chen YR, Chen PK. Unusual complications of the Le Fort I osteotomy. Plast Reconstr Surg 1995;96: 1289-96.

2. Cheng HC, Chi LH, Wu JY, Hsieh TT, Pemg BY. Blindness and basal ganglia hypoxia as a complication of Le Fort I osteotomy attributable to hypoplasia of the internal carotid artery: a case report. Oral Surg Oral Med Oral Pathol Oral Radiol Endod 2007;104:e27-33.

3. Dolanmaz D, Esen A, Emlik D, Candirli C, Kalayci A, Ciçekcibaşi A. Comparison of two different approaches to the pterygomaxillary junction in Le Fort I osteotomy. Oral Surg Oral Med Oral Pathol Oral Radiol Endod 2008;106:e1-5.

4. Lanigan DT, Guest P. Alternative approaches to pterygomaxillary separation. Int J Oral Maxillofac Surg 1993;22:131-8.

5. Lanigan DT, Loewy J. Postoperative computed tomography scan study of the pterygomaxillary separation during the Le Fort I osteotomy using a micro-oscillating saw. J Oral Maxillofac Surg 1995;53:1161-6.

6. Laster Z, Ardekian L, Rachmiel A, Peled M. Use of the 'shark-fin' osteotome in separation of the pterygomaxillary junction in Le Fort I osteotomy: a clinical and computerized tomography study. Int J Oral Maxillofac Surg 2002;31:100-3.

7. Cruz AA, dos Santos AC. Blindness after Le Fort I osteotomy: a possible complication associated with pterygomaxillary separation. J Craniomaxillofac Surg 2006;34:210-6.

8. Kim JW, Chin BR, Park HS, Lee SH, Kwon TG. Cranial nerve injury after Le Fort I osteotomy. Int J Oral Maxillofac Surg 2011;40:327-9.

9. Bhaskaran AA, Courtney DJ, Anand P, Harding SA. A complication of Le Fort I osteotomy. Int J Oral Maxillofac Surg
2010;39:292-4.

10. Lanigan DT, Hey JH, West RA. Major vascular complications of orthognathic surgery: hemorrhage associated with Le Fort I osteotomies. J Oral Maxillofac Surg 1990;48:561-73.

11. O'Regan B, Bharadwaj G. Pterygomaxillary separation in Le Fort I osteotomy UK OMFS consultant questionnaire survey. Br J Oral Maxillofac Surg 2006;44:20-3.

12. Newhouse RF, Schow SR, Kraut RA, Price JC. Life-threatening hemorrhage from a Le Fort I osteotomy. J Oral Maxillofac Surg 1982;40:117-9.

13. Albernaz VS, Tomsick TA. Embolization of arteriovenous fistulae of the maxillary artery after Le Fort I osteotomy: a report of two cases. J Oral Maxillofac Surg 1995;53:208-10.

14. Habal MB. A carotid cavernous sinus fistula after maxillary osteotomy. Plast Reconstr Surg 1986;77:981-7.

15. Regan BO, Bharadwaj G. The identification and protection of the descending palatine artery in Le Fort I osteotomy: a forgotten technique? Br J Oral Maxillofac Surg 2007;45:412-4.

16. Li KK, Meara JG, Alexander A Jr. Location of the descending palatine artery in relation to the Le Fort I osteotomy. J Oral Maxillofac Surg 1996;54:822-5.

17. Lee IG, Myoung H, Hwang SJ, et al. Location of the descending palatine artery in relation to the Le Fort I osteotomy in Koreans. J Korean Assoc Maxillofac Plast Reconstr Surg 2007; 29:509-12.

18. Kanazawa T, Kuroyanagi N, Miyachi $\mathrm{H}$, et al. Factors predictive of pterygoid process fractures after pterygomaxillary separation without using an osteotome in Le Fort I osteotomy. Oral Surg Oral Med Oral Pathol Oral Radiol 2013;115:310-8.

19. Hwang K, Lee DK, Chung IH, Lee SI. Le Fort I osteotomy with sparing fracture of lateral pterygoid plate. J Craniofac Surg 2001;12:48-52.

20. Lee SH, Lee SH, Mori Y, Minami K, Park HS, Kwon TG. Evaluation of pterygomaxillary anatomy using computed tomography: are there any structural variations in cleft patients? J Oral Maxillofac Surg 2011;69:2644-9.

21. Robinson PP, Hendy CW. Pterygoid plate fractures caused by the Le Fort I osteotomy. Br J Oral Maxillofac Surg 1986;24: 198-202.

22. Trimble LD, Tideman H, Stoelinga PJ. A modification of the pterygoid plate separation in low-level maxillary osteotomies. J Oral Maxillofac Surg 1983;41:544-6.

23. Cheng LH, Robinson PP. Evaluation of a swan's neck osteotome for pterygomaxillary dysjunction in the Le Fort I osteotomy. Br J Oral Maxillofac Surg 1993;31:52-3.

24. Precious DS, Morrison A, Ricard D. Pterygomaxillary separation without the use of an osteotome. J Oral Maxillofac Surg 1991;49:98-9.

25. Stajcic Z. Altering the angulation of a curved osteotome--does it have effects on the type of pterygomaxillary disjunction in Le Fort I osteotomy? An experimental study. Int J Oral Maxillofac Surg 1991;20:301-3.

26. Landes CA, Stübinger S, Rieger J, Williger B, Ha TK, Sader R. Critical evaluation of piezoelectric osteotomy in orthognathic surgery: operative technique, blood loss, time requirement, nerve and vessel integrity. J Oral Maxillofac Surg 2008; 66:657-74.

27. Ueki K, Nakagawa K, Marukawa K, Yamamoto E. Le Fort I osteotomy using an ultrasonic bone curette to fracture the pterygoid plates. J Craniomaxillofac Surg 2004;32:381-6. 